\title{
Fostering in the African striped mouse: implications for kin recognition and dominance
}

\author{
Neville PILLAY
}

Pillay N. 2000. Fostering in the African striped mouse: implications for kin recognition and dominance. Acta Theriologica 45: 193-200.

Fostering was studied in the African striped mouse Rhabdomys pumilio (Sparrman, 1784 ) in captivity to establish if females can distinguish their own from strange pups, and if fostering affected the biology of fostered pups. In experiment 1, I exchanged 3-4 same-age pups between two litters; their acceptance by the foster mother and their growth rate were studied from 0 to 16 days of age. In experiment 2, the acceptance of pups fostered at 2 days of age and returned to their natural mothers between 4 and 16 days of age was ascertained. All pups younger than 10 and 12 days of age were accepted in experiment 1 and 2, respectively. Slow growth rates were recorded only for pups fostered at 10 days old. Females appeared not to distinguish their own pups from strange pups, until the pups started eating solid food. In experiment 3 , the dominance-subordinate relationship between sexually mature fostered and normally-reared individuals was established in dyadic encounters. Pups fostered at 4-6 days were equally likely to win or lose an encounter, whereas pups fostered at 8-10 days were significantly more likely to win an encounter. It appears that fostering affects the later dominant behaviour of some fostered young.

Ecophysiological Studies Research Programme (ESRP), Department of Zoology, University of the Witwatersrand, Private Bag 3, Wits 2050, South Africa, e-mail: NevilleP@gecko.biol.wits.ac.za

Key words: Rhabdomys pumilio, fostering, kin recognition, dominance, reproduction

\section{Introduction}

Mammalian mothers enhance their reproductive fitness by caring only for their own offspring, and in doing so must distinguish between their own and unfamiliar young (Leon 1983). Mothers of colonial species normally restrict care to their own offspring (ie do not participate in communal nursing). For example, rodent mothers select their own pups over strange conspecific pups (Fullerton et al. 1974) and are likely to kill foreign pups (Leon 1983). Mothers of colonial species must employ specific cues to identify their young, and olfactory cues are usually implicated in this identification process (Beauchamp 1976, Leon 1983). These olfactory cues may be produced by the pups themselves or are placed on the pups by the mother (Leon 1975). In contrast, Walser (1977) maintains that females of solitary species recognise the nest (perhaps by a characteristic nest odour) rather than the individual pups which occupy it. Such recognition is regarded as spatially-based recognition by Halpin (1991), and leads to a situation whereby mothers are likely to 
respond preferentially to any young (related or unrelated) in the nest. Consequently, one can experimentally manipulate litters by simply placing young into a foreign nest (ie foster young).

Despite the lack of discrimination between strange and familiar young, some studies have shown that mothers of solitary species become more discriminating as the pups develop. They are able distinguish their own young from strangers when young become mobile and/or at the onset of weaning (Walser 1977, Westlin 1995).

The objectives of this study were to establish whether females could distinguish between their own and strange pups, and to establish if the fostering process affected the biology of fostered pups. Three hypotheses were tested in this study. Firstly, it was predicted that females would show temporal variation in the ability to distinguish between their own and strange pups. Mothers would accept younger pups by suckling and grooming them, but reject older pups by attacking them. As a result of their acceptance/rejection by foster mothers, the growth rate of pups fostered later would be slower than those fostered earlier. Secondly, because mothers associated with the pups before fostering, a female, whose pups were fostered early in life, would accept her pups even when they were returned to her at a later age. Thirdly, fostered pups would be aversely affected by the fostering process, particularly those fostered close to weaning age. Pups fostered at an older age would be more likely to lose dominant-subordinate encounters with non-fostered pups than those fostered soon after birth. It is known that the early social and physical environment of young animals, within a natural range of variation, determines later phenotypic characteristics of the offspring (Namikas and Wehmer 1978, Rossiter 1996), such as social behaviour (Batzli et al. 1977, Grau 1982, Holmes and Sherman 1982, Blaustein 1983, Ferkin and Rutka 1990, Laviola and Alleva 1995).

I tested these predictions in the African striped mouse Rhabdomys pumilio (Sparrman, 1784). This rodent has a wide distribution in southern Africa (Skinner and Smithers 1990). In areas of more than adequate cover and which are not resource-limited during the breeding season (eg eastern parts of South Africa), breeding females maintain discrete, non-overlapping territories (Willan and Meester 1989). A high incidence of female infanticide of unfamiliar weanlings (Marais 1974) may be the underlying reason for such female territoriality (Willan 1982).

\section{Material and methods}

\section{General methods}

A breeding colony of $R$. pumilio was started in 1995 at the University of the Witwatersrand. The captive population was derived from individuals live-trapped from Alice $\left(32^{\circ} 48^{\prime} \mathrm{S}, 26^{\circ} 52^{\prime} \mathrm{E}\right)$, Eastern Cape Province, South Africa. When the present study was conducted, the colony comprised a mix of wild-caught pairs, and $F_{1}$ and $F_{2}$ pairs. Selected litters of all these pairs were used in three experiments (below).

Breeding took place in a room with partial environmental control (light regime of $14 \mathrm{~L}: 10 \mathrm{D}$, lights on at $\left.05.00 \mathrm{~h}, 20-24^{\circ} \mathrm{C}, 30-60 \% \mathrm{rH}\right)$. Breeding pairs were housed in $400 \times 250 \times 120 \mathrm{~mm}$ Lab-o-tec ${ }^{\mathrm{R}}$ 
cages. Coarse wood shavings were provided as litter, and animals used hay as nesting material. $\mathrm{Epol}^{\mathrm{R}}$ mouse cubes, $\mathrm{Epol}^{\mathrm{R}}$ dog cubes and water were provided ad libitum; apples were provided weekly.

All females used in this experiment had previously produced at least one litter in captivity. Sires were removed from the breeding cage and housed elsewhere a few days before parturition. Only litters comprising 6-8 individuals were used in experiments; mean litter size of the breeding colony $=7.2$ $(\mathrm{SD}=1.8, n=94$ litters). Fostering involved pups between day 0 , date of birth, to day 16, weaning.

\section{Experiment 1}

In the first experiment, the acceptance or rejection of strange pups by females was tested over several age categories. In addition, the growth rate of fostered pups for the period from fostering to weaning was established and compared to those of pups raised normally.

Tests involved exchanging same-age offspring between two unrelated mothers. This was possible due to the frequent occurrence of synchronous births in the breeding colony. When pups of two litters reached an appropriate age (eg 10 days old), 3 or 4 pups from litters of $6-7$ or 8 pups respectively were randomly selected, removed from their mother, marked on the dorsal aspect of the base of the tail with a non-toxic marker (Gentian violet), and introduced into the other litter. Based on the original litter size, females donated 3 or 4 pups and received 3 or 4 pups. The sex of the pups was not determined prior to fostering. Pups that remained with their mothers (designated own pups) were marked on the mid-dorsal part of the tail with Gentian Violet. Markings were darkened every 3-4 days when the previous markings began to fade. The number of pups accepted by foster females was calculated by age category, and differences among age categories were statistically tested using the $\chi^{2}$-test for proportions (Zar 1996).

All pups (own and foster) were weighed every second day from day 0 to weaning (ie 16 days of age). Growth rates, defined as the change in mass expressed as grams per day, were established for the period from fostering to weaning (day 16). Mean growth rates were calculated for the mother's own and her foster pups. These data sets were compared with each other and with those of the breeding colony using a one-way ANOVA.

\section{Experiment 2}

In the second experiment, pups were fostered and returned to their mothers at a later age. Following the same protocol as in the first experiment, same-age pups were exchanged between litters, but pups were fostered only when they were 2 days old. Females were then assigned to one of seven treatments. In the first treatment, all fostered pups in a litter were returned to their mothers at 4 days old (ie after spending two days with a foster mother). In the six other treatments, pups spent increasing periods (ie increasing by 2 days for each treatment) with the foster mother before being returned to their natural mothers. The number of returned pups accepted by the mother was calculated, and differences among age categories were statistically tested using the $\chi^{2}$-test for proportions (Zar 1996).

\section{Experiment 3}

In the third experiment, the dominant-subordinate relationships of the following same-sex dyads were studied: (i) fostered individuals and individuals from the colony that were never used in experiments, and (ii) individuals raised with foster pups and individuals that were raised in the colony. Fostered individuals and those individuals raised with foster pups were those derived from experiment 1. These mice were tested when they were 60 days of age and sexually mature (Pillay 1999). All animals were weighed to the nearest $0.1 \mathrm{~g}$ immediately before their encounter, and only individuals weighing within $10 \mathrm{~g}$ of each other were used. In addition, members of a dyad were unfamiliar to one another. All animals underwent a single dyadic encounter.

Encounters were staged in a neutral arena (ie glass aquarium; $450 \times 300 \times 300 \mathrm{~mm}$ ), the floor of which was covered with a $2 \mathrm{~cm}$ layer of coarse wood shavings. Aquaria were thoroughly cleaned after every encounter. Prior to observations, the arena was divided into two parts with a removable opaque partition. Members of a dyad were placed on either side of the partition. Following a 5 minutes 
acclimation period, the partition was removed and the first 15 minutes of interaction video-recorded. Recordings were made under white light using a Sony Handycam CCD-TR880F camera recorder and a Sharp VC-MH80 video recorder.

The methods of Colvin (1973) and Cranford and Derting (1983) were used to identify the dominant and subordinate individuals in each dyad. An animal was classified as dominant if, in comparison to its opponent, it exhibited more exploratory activity and aggressive behaviour (Colvin 1973). In encounters where the outcome was unclear, neither animal was considered dominant and a tie was declared. A $\chi^{2}$ analysis was used to ascertain differences in the number of times fostered and own individuals won an encounter. Separate analyses were performed in respect of the age category of fostering (ie age at fostering; Experiment 1).

\section{Results}

\section{Experiment 1}

There was a significant difference in terms of the acceptance or rejection of foster pups $\left(\chi^{2}=78.24, \mathrm{df}=8, p<0.001\right)$. All foster pups between 0 and 8 days of age were accepted by the foster mother (Table 1). No foster pups of $12-16$ days old were accepted by foster mothers (Table 1). Thus, it appears that the threshold age dividing acceptance/rejection of foster pups is near 10 days of age.

Pups fostered at 12 days of age or later encountered severe aggression (ie chasing and biting) from foster mothers minutes after introduction, and were removed immediately afterwards and returned to their mothers or weaned. Females never showed aggression towards their own pups. Foster pups that were accepted by the foster mother ( $0-8$ days old) were allowed to suckle her until weaning-age, even though $42 \%$ of 8 and $87 \%$ of 10 day old foster pups were eating solid food at introduction.

Those 10 day old pups that were accepted had a significantly slower growth rate after fostering than did own pups and other pups in the colony (Table 2). At other ages (2-8 days), the growth rate of own and foster pups was similar before and after fostering (Table 2).

Table 1. Number of litters and pups involved in fostering experiments in respect of the age of foster pups at introduction, and percentage of foster pups accepted by foster mothers.

\begin{tabular}{lrcc}
\hline \multirow{2}{*}{$\begin{array}{l}\text { Age (days) of pups } \\
\text { at introduction }\end{array}$} & \multicolumn{2}{c}{ Number fostered } & \\
\cline { 2 - 3 } & Litters & Pups & \\
\hline 0 & 8 & 32 & 100 \\
2 & 10 & 32 & 100 \\
4 & 8 & 28 & 100 \\
6 & 10 & 36 & 100 \\
8 & 8 & 30 & 100 \\
10 & 12 & 38 & 82 \\
12 & 14 & 40 & 0 \\
14 & 16 & 56 & 0 \\
16 & 8 & 30 & 0 \\
\hline
\end{tabular}


Table 2. Mean \pm SD growth rate $\left(\mathrm{g} \cdot \mathrm{day}^{-1}\right)$ of own and foster pups for the age of introduction indicated. Growth rates are given from day of introduction to 16 days old. Data from the breeding colony at the appropriate time intervals are given as comparison. Number of litters as in Table 1 for own and foster pups and 38 litters for colony data. * - Data not given after 10 days old as no foster pups were accepted after this time. ns - non-significant.

\begin{tabular}{lcccrcr}
\hline \multirow{2}{*}{$\begin{array}{l}\text { Age (days) of pups } \\
\text { at introduction }\end{array}$} & Own & Foster & Colony & \multicolumn{3}{c}{ One-way ANOVA } \\
\cline { 5 - 7 } & & & & $F$ & $\mathrm{df}$ & $p$ \\
\hline 0 & $0.85 \pm 0.08$ & $0.84 \pm 0.10$ & $0.85 \pm 0.08$ & 0.14 & 2,53 & $\mathrm{~ns}$ \\
2 & $0.85 \pm 0.06$ & $0.84 \pm 0.05$ & $0.81 \pm 0.07$ & 1.56 & 2,56 & $\mathrm{~ns}$ \\
4 & $0.78 \pm 0.08$ & $0.74 \pm 0.11$ & $0.73 \pm 0.09$ & 0.87 & 2,53 & $\mathrm{~ns}$ \\
6 & $0.75 \pm 0.06$ & $0.76 \pm 0.10$ & $0.75 \pm 0.07$ & 0.11 & 2,57 & $\mathrm{~ns}$ \\
8 & $0.81 \pm 0.09$ & $0.82 \pm 0.08$ & $0.77 \pm 0.09$ & 0.10 & 2,53 & $\mathrm{~ns}$ \\
$10^{*}$ & $0.85 \pm 0.20$ & $0.60 \pm 0.17$ & $0.80 \pm 0.11$ & 11.26 & 2,61 & $<0.001$ \\
\hline
\end{tabular}

\section{Experiment 2}

The results of experiment 2 were very similar to those of experiment 1 . Mothers accepted all returned pups that were 10 days old or younger, whereas mothers were aggressive to and rejected $26 \%$ of 12 day old pups and $100 \%$ of 14 and 16 day old pups (Table 3). The acceptance of pups over the different ages was statistically significant $\left(\chi^{2}=53.62, \mathrm{df}=6, p<0.001\right)$.

\section{Experiment 3}

Table 4 gives the percentage of times that fostered and own individuals won their encounters in same-sex dyadic encounters with normally-reared individuals. Individuals raised with foster pups were equally likely to win an encounter as were the individuals raised in the colony (Table 4). Likewise, individuals fostered on days 4 and 6 equally won or lost encounters with normally-reared individuals.

Table 3. Number of litters and pups re-united involved in fostering experiments in respect of the age of foster pups at introduction, and percentage of foster pups accepted by foster mothers.

\begin{tabular}{lccc}
\hline \multirow{2}{*}{$\begin{array}{l}\text { Age (days) of } \\
\text { re-united pups }\end{array}$} & \multicolumn{2}{c}{ Number fostered } & \\
\cline { 2 - 3 } & Litters & Pups & \\
\hline 4 & 10 & 33 & 100 \\
6 & 10 & 32 & 100 \\
8 & 10 & 33 & 100 \\
10 & 10 & 36 & 100 \\
12 & 10 & 35 & 74 \\
14 & 10 & 31 & 0 \\
16 & 10 & 33 & 0 \\
\hline
\end{tabular}




\begin{tabular}{|c|c|c|c|c|}
\hline \multirow{2}{*}{$\begin{array}{l}\text { Age when involved in } \\
\text { fostering experiments }\end{array}$} & \multicolumn{2}{|c|}{ Females } & \multicolumn{2}{|c|}{ Males } \\
\hline & Foster & Own & Foster & Own \\
\hline 4 & $\begin{array}{l}53.3 \\
(30)\end{array}$ & $\begin{array}{l}50.0 \\
(24)\end{array}$ & $\begin{array}{l}48.1 \\
(27)\end{array}$ & $\begin{array}{l}50.0 \\
(16)\end{array}$ \\
\hline 6 & $\begin{array}{l}75.0^{* *} \\
(20)\end{array}$ & $\begin{array}{l}52.9 \\
(17)\end{array}$ & $\begin{array}{l}57.9 \\
(19)\end{array}$ & $\begin{array}{l}60.0 \\
(20)\end{array}$ \\
\hline 8 & $\begin{array}{l}82.4^{* *} \\
(17)\end{array}$ & $\begin{array}{l}58.8 \\
(17)\end{array}$ & $\begin{array}{l}78.9^{*} \\
(19)\end{array}$ & $\begin{array}{l}50.0 \\
(16)\end{array}$ \\
\hline 10 & $\begin{array}{l}75.0^{*} \\
(20)\end{array}$ & $\begin{array}{l}40.9 \\
(22)\end{array}$ & $\begin{array}{l}81.2^{*} \\
(16)\end{array}$ & $\begin{array}{l}46.2 \\
(13)\end{array}$ \\
\hline
\end{tabular}

Individuals fostered on days 8 and 10 won significantly more encounters than their normally-reared dyadic partners.

\section{Discussion}

The results in the first experiment support the first prediction of the study that females are likely to accept strange pups that were younger than those fostered closer to the time of weaning, confirming the findings reported in another African rodent (Saccostomus campestris; Westlin 1995). In addition, those pups fostered earlier showed similar growth rates to non-fostered pups, but young fostered at a later age had reduced growth rates.

From 12 days of age onwards, female striped mice displayed overt aggression to foster pups. The only difference between foster pups before and after 10 days old (ie threshold age for acceptance/rejection) was age and diet. Since captive $R$. pumilio females were highly tolerant of their offspring beyond the age of weaning (Pillay 1999), diet and not age may be the factor influencing successful fostering.

Young R. pumilio are weaned at 15-16 days of age (Brooks 1982, Pillay 1999), although young start eating food as early as 10 days old, from which time the incidence of suckling decreases steadily until weaning (Brooks 1982). Thus, the important difference between young fostered before and after 10 days of age is that the latter group were eating solid food. Until 8 days of age, foster pups were accepted (suckled and groomed) by the foster mother. Similarly, Westlin (1995) maintains that suckling of foster pups inhibits their rejection by lactating foster mothers. At 10 days of age, fostered striped mouse pups were tolerated by the foster mother but were not allowed to suckle (N. Pillay, pers. obs.). This observation 
supports the data on growth rates which indicates comparatively low growth rate values for 10 day old foster pups. I speculate these foster pups may have received limited opportunities to suckle the foster mother, and during this time, they may have eaten mainly solid food.

The prediction that a mother would accept their pups when they were returned to her after a period of separation was partially supported by results from experiment 2 . Although young pups were accepted, there was a breakdown in kin recognition of older pups, since biological mothers rejected pups returned after 10 days of age. If the results from experiments 1 and 2 are considered together, it would appear that female striped mice do not distinguish between their own and foster offspring, but between pups that are suckling and those eating solid food. Similar conclusions were reached in a study of pouched mouse $S$. campestris (Westlin 1995).

The results from experiment 3 do not support the prediction that fostered offspring are more likely to lose an encounter than non-fostered offspring. Individuals fostered at a later age (ie closer to weaning) had a significantly higher proportion of wins during encounters with normally-reared individuals. This suggests that their social behaviour is potentially affected by fostering, particularly during the pre-weaning environment. The literature suggests that either or both of two factors may be implicated. Firstly, undernourishment during early life has been shown to result in more competitive and aggressive adult individuals (Tonkiss and Smart 1983, Mendl and Paul 1990b, Wong and Bondrup-Nielsen 1992). The undernutrition hypothesis remains speculative since the results obtained in the present study are ambiguous. While individuals fostered on day 10 had slower growth rates and won many of their encounters, the growth rates of pups fostered on day 8 were similar to other colony offspring yet these individuals were dominant in most of their encounters. Secondly, intra-litter competition before weaning, usually for access to the mother's nipples, may lead to increased fighting during later life, as demonstrated in the house mouse (Mendl and Paul 1990a). Clearly, both these predictions need to be tested.

Acknowledgements: Thanks to R. Baxter for providing wild-caught animals, G. du Preez for technical assistance, D. Padiachy and L. Bennett for reading an earlier version of the manuscript, and the University Research Committee of the University of Witwatersrand for financial support. Animal ethics clearance number: AESC 96/22/2a.

\section{References}

Batzli G. O., Getz L. L. and Hurley S. S. 1977. Suppression of growth and reproduction of microtine rodents by social factors. Journal of Mammalogy 58: 583-591.

Beauchamp G. K. 1976. Diet influences attractiveness of urine in guinea pigs. Nature 263: 587-588.

Blaustein A. R. 1983. Kin recognition mechanisms: phenotypic matching or recognition alleles? The American Naturalist 121: 749-754.

Brooks P. M. 1982. Aspects of the reproduction, growth and development of the four-striped field mouse, Rhabdomys pumilio (Sparrman, 1784). Mammalia 46: 53-64. 
Colvin D. V. 1973. Agonistic behavior in males of five species of voles Microtus. Animal Behaviour 21: 471-480.

Cranford J. A. and Derting T. L. 1983. Intra and interspecific behavior of Microtus pennsylvanicus and Microtus pinetorum. Behavioral Ecology and Sociobiology 13: 7-11.

Ferkin M. H. and Rutka T. K. 1990. Mechanisms of sibling recognition in meadow voles. Canadian Journal of Zoology 68: 609-613.

Fullerton C., Berryman J. C. and Porter R. H. 1974. On the nature of mother-infant interactions in the guinea pig (Cavia porcellus). Behaviour 48: 145-156.

Grau H. J. 1982. Kin recognition in white-footed deermice (Peromyscus leucopus). Animal Behaviour 30: 497-505.

Halpin Z. T. 1991. Kin recognition cues of vertebrates. [In: Kin recognition. P. G. Hepper, ed]. Cambridge University Press, Cambridge: 220-258.

Holmes W. G. and Sherman P. W. 1982. The ontogeny of kin recognition in two species of ground squirrels. American Zoology 22: 491-517.

Laviola G. and Alleva E. 1995. Sibling effects on the behavior of infant mouse litters (Mus domesticus). Journal of Comparative Psychology 109: 68-75.

Leon M. 1975. Dietary control of maternal pheromone in the lactating rat. Physiology and Behaviour 14: 311-319.

Leon M. 1983. Chemical communication in mother-young interactions. [In: Pheromones and reproduction in mammals. J. G. Vandenbergh, ed]. Academic Press, London: 39-77.

Marais F. J. 1974. The behaviour and population dynamics of a confined colony of striped mice (Rhabdomys pumilio). M Sc thesis, University of Pretoria, Pretoria: 1-200.

Mendl M. and Paul E. S. 1990a. Parental care, sibling relationships and the development of aggressive behaviour in two lines of wild house mice. Behaviour 116: 11-41.

Mendl M. and Paul E. S. 1990b. Litter composition affects parental care, offspring growth and the development of aggressive behaviour in wild house mice. Behaviour 116: 90-108.

Namikas J. and Wehmer F. 1978. Gender composition of the litter affects behavior of male mice. Behavioral Biology 23: 219-224.

Pillay N. 1999. The effects of sibling reproduction in the African striped mouse. Acta Theriologica 44: 291-298.

Rossiter M. C. 1996. Incidence and consequences of inherited environmental effects. Annual Review of Ecology and Systematics 27: 451-476.

Skinner J. D. and Smithers R. H. N. 1990. The mammals of the southern African subregion. University of Pretoria, Pretoria: 1-771.

Tonkiss J. and Smart J. L. 1983. Interactive effects of genotype and early life under-nutrition on the development of behaviour in rats. Developmental Psychobiology 16: 287-301.

Walser E. S. 1977. Maternal behaviour in mammals. [In: Comparative aspects of lactation. M. Peaker, ed]. Symposia of the Zoological Society of London, Academic Press, New York: 313-331.

Westlin L. M. 1995. Fostering in an African rodent, Saccostomus campestris (Cricetidae). Journal of Zoology, London 237: 163-167.

Willan K. 1982. Social ecology of Otomys irroratus, Rhabdomys pumilio and Praomys natalensis. $\mathrm{Ph} \mathrm{D}$ thesis, University of Natal, Pietermaritzburg: 1-294.

Willan K. and Meester J. 1989. Life history tactics of southern African Mastomys natalensis, Otomys irroratus and Rhabdomys pumilio (Mammalia, Rodentia). [In: Alternative life history styles of animals. M. N. Bruton, ed]. Kluwer, Dordrecht: 421-439.

Wong K. L. and Bondrup-Nielsen S. 1992. Long-term effects of infant malnutrition on the behaviour of adult meadow voles, Microtus pennsylvanicus. Canadian Journal of Zoology 70: 1304-1308.

Zar J. H. 1996. Biostatistical analysis. 3rd edition. Prentice Hall International, Inc., London: 1-662.

Received 30 June 1998, accepted 15 August 1999. 